Analitika: Jurnal Magister Psikologi UMA, Vol. 11 (2) Desember (2019)

ISSN: 2085-6601 (Print), ISSN: 2502-4590 (Online)

DOI: http://dx.doi.org/analitika.v11i1.2930

ANALITIKA

Jurnal Magister Psikologi UMA

Available online http://ojs.uma.ac.id/index.php/analitika

\title{
Model Konseling Kelompok dengan Teknik Realitas Mengenai Gaya Hidup Hedonisme pada Mahasiswa
}

\author{
Group Counseling Model with Reality Technique \\ about Hedonism Lifestyle in Students
}

\author{
Nurasyah* \\ Program Studi Bimbingan Konseling, Fakultas Keguruan dan Ilmu Pendidikan \\ Universitas Muslim Nusantara Al Washliyah, Indonesia
}

Diterima: 6 Oktober 2019, disetujui: 28 Desember 2019, dipublish: 30 Desember 2019

*Corresponding author: E-mail: nurasyah@umnaw.ac.id

\begin{abstract}
Abstrak
Fenomena gaya hidup hedonisme semakin marak dengan adanya tempat hiburan malam, dapat dilihat dari banyaknya remaja yang sering nongkrong di café, dan bahkan clubbing pada malam hari serta mencari kesenangan hidup dengan main diluar rumah serta membeli barang-barang mahal untuk memenuhi kesenangan. Gaya hidup hedonisme sangat berkaitan dengan pergaulan dan pemahaman tentang jati diri remaja. Tujuan penelitian ini adalah untuk mencegah gaya hidup hedonisme mahasiswa bimbingan konseling melalui model konseling kelompok dengan teknik realita. Sampel penelitian ini adalah 10 orang mahasiswa yang ditentukan secara purposive sampling. Penelitian ini menggunakan metode penelitian eksperimen. Instrumen yang digunakan dalam penelitian ini berupa angket gaya hidup hedonisme. Dari hasil perhitungan diperoleh t_hitung= 40,9 sedangkan harga t_tabel dengan d.b $=\mathrm{N}-1=10-1=9$ pada taraf nyata $=0,05$ diperoleh sebesar 2,262. Sehingga t_hitung $>t_{\_}$tabel atau $(40,9>2,262)$. Berdasarkan hal tersebut maka dapat dinyatakan bahwa hipotesis penelitian ini model konseling kelompok dengan teknik realitas terhadap gaya hidup hedonisme mahasiswa BK UMN Al Washliyah Tahun Ajaran 2018/2019 dapat diterima dan berdampak positif terhadap perubahan gaya hidup hedonisme mahasiswa bimbingan konseling. Kata kunci: Model layanan konseling kelompok, gaya hidup hedonisme, teknik realitas, mahasiswa
\end{abstract}

\begin{abstract}
The phenomenon of hedonism lifestyle is increasingly prevalent with nightclubs, it can be seen from the many teenagers who often hang out at cafes, and even clubbing at night also looking for the pleasure of life by playing outside the home and buying expensive items to fulfill their pleasures. Because this hedonism lifestyle is closely related to the association and understanding of teenage identity. The purpose of this study is to prevent the hedonism lifestyle of student counseling guidance through group counseling models with reality techniques. The sample of this study was 10 students who were determined by purposive sampling. This study uses an experimental research method. The instrument used in this study was a hedonism lifestyle questionnaire. From the calculation results obtained t_calculate $=40.9$ while the price of ttable with $d . b=N-1=10-1=9$ at the real level $=0.05$ obtained by 2.262. So that $t_{-}$count $>$t_table or (40.9> 2.262). Based on this, it can be stated that the hypothesis of this study "a group counseling model with a reality technique on the lifestyle of hedonism students of BK UMN Al Washliyah in the 2018/2019 Academic Year can be accepted and has a positive impact on lifestyle changes in student hedonism counseling guidance.
\end{abstract}

Keywords: Group counseling model, hedonism lifestyle, reality technique, students

How to Cite: Nurasyah. (2019), Model Konseling Kelompok dengan Teknik Realitas Mengenai Gaya Hidup Hedonisme pada Mahasiswa, Analitika: Jurnal Magister Psikologi UMA, 11 (2): 137 - 143 


\section{PENDAHULUAN}

Remaja biasanya selalu memiliki rasa penasaran yang besar sehingga mempengaruhi mereka mencoba sesuatu hal baru. Keadaan saat ini tahap pencarian jati diri. Hipnotis gaya hidup hedonisme begitu kuat membuat pikiran remaja kebanyakan lebih berkeinginan untuk hidup enak, mewah dan berkecukupan. Label remaja modis dan moderen akan melekat pada diri remaja apabila mereka bisa mengikuti tren dan mode masa kini agar mereka terlihat populer. Maraknya mall, kafe dan klub atau tempat hiburan malam yang ada memberikan pengaruh terhadap penampilan maupun gaya hidup remaja saat ini.

Dan pada kenyataaannya banyak sekarang di dunia remaja yang sangat membutakan dan tanpa tau apa efek yang sangat terus-menerus mempengaruhi gaya hidup remaja, dengan rasa penasaran yang besar bahkan mencoba-coba hal-hal yang tidak seharusnya dilakukan. Dan dilakukan hanya demi kesenangan bahkan kepuasaan semata. Fenomena gaya hidup hedonisme bertambah menonjol dengan adanya tempat-tempat duduk-duduk berupa kafe dan mengikuti gaya hidup orang eropa sering ke klub serta mengikuti ego remaja mencoba mencari kesenangan dengan keluar rumah sampai larut malam bahkan pulang menjelang pagi hari, membeli barang-barang branded untuk memenuhi kepuasan hatinya.

Gaya hidup adalah bentuk identitas kolektif yang berkembang seirama dengan waktu, bahkan dalam kesenangan baru yang sesekali terlihat menyimpang mereka mungkin secara implicit berhubungan dengan aspek-aspek memori kolektif.(David Chaney, 2006)

Hedonisme adalah salah satu teori lama, paling simpel, paling kaku, dan akan selalu kita temukan kembali. Dan kebanyakan orang belum bisa merangkum filsafat hidup mereka sendiri, Bentuk aliran ini adalah bentuk kesenangan dengan tujuan akhir hidup yang memiliki manset yang tinggi. (Poespoprodjo, 1999)

Kaum hedonisme modern memilih kata kebahagiaan untuk kesenangan. Maka hendaknya kita berhati-hati dalam membaca buku-buku mereka sebab bila bicara tentang kebahagiaan, mereka betul-betul hanya memaksudkan kesukaan hidup ini saja. Budaya hedonisme adalah pandangan bahwa yang sungguh baik bagi manusia adalah kesenangan. Kenikmatan biasanya bersifat jasmani saja karena tidak lain kesenangan meruapakan bagian jasmaniah. Ada tiga kemungkinan: 1) gerak yang kasar adalah ketidaksenangan, 2) gerak yang halus adalah kesenangan, 3) tiadanya gerak adalah netral.

Gaya hidup hedonis adalah gaya hidup yang orientasi aktivitasnya lebih kearah kesenangan jasmaniah, seperti berada ditempat-tempat tongkrongan, berbelanja di supermall, menghabiskan waktu melalui sosmed, berfoya-foya agar menjadi perhatian orang lain. (Amstrong, 2003). Gaya hidup antara individu satu dengan yang lainnya akan berbeda. Gaya hidup hidup merupakan fashion seseorang dalam kehidupan pribadinya, dan perilaku hidupnya dimasyarakat agar dipandang berbeda dengan yang hidup hidup merupakan fashion seseorang dalam kehidupan pribadinya, dan perilaku hidupnya dimasyarakat agar 
dipandang berbeda dengan yang lainnya, sehingga menjadi pusat perhatian orang lain.

Mahasiswa sebagai individu memiliki kecenderungan yang berbeda dalam menuangkan gaya hidupnya sehari-hari. Mahasiswa yang senang mengisi waktu luangnya di mall dan kafe inilah yang merupakan mahasiswa yang memiliki karakteristik gaya hidup hedonis. Ciri-ciri gaya hidup hedonisme menurut Rahardjo dan Silalahi (2007) yaitu kebanyakan orang yang berada di kota besar dengan gampang memperoleh akses informasi melalui teknologi informasi, orang-orang yang memiliki materi lebih atau termasuk kalangan orang berada akan selalu mengikuti perkembangan zaman dan tidak akan mau ketinggalan fashion yang trend seperti yang ada di sosmed maupun majalah agar tidak dibilang oleh kalanagan mereka sebagai orang yang udik atau kuno lebih dominan akan terpengaruh gaya hidupnya mengarah kegaya hidup hedinism.

Sedangkan menurut Susanto (2001: 33) gaya hidup hedonisme yaitu orang yang suka meluangkan waktunya ditempat nongkrong, seperti cafe, Bersenang-senang di cafe tidak harus melakukan hal-hal yang negatif seperti dengan minuman beralkohol namun menghabiskan waktu untuk beristirahat dan bersantai untuk menunjukan statusnya.

Dapat disimpulkan bahwa kebanyak mahasiswa lebih cenderung mengikuti gaya hidup hedonidme dan hal ini dapat berdampak buruk terhadap perkembangan potensi diri mahasiswa.

Melalui kegiatan layanan konseling kelompok dengan teknik realitas ini diharapkan menjadi suatu pemahaman bagi mahasiswa tentang gaya hidup hedonisme Berdasarkan penjelasan diatas masalah kepercayaan diri yang terjadi pada mahasiswa atau peserta didik merupakan persoalan yang penting dan mendesak untuk dicari penyelesaiannya.

Konseling kelompok merupakan bagian untuk memberikan pertolongan kepada individu (mahasiswa) dengan perantara kegiatan kelompok yang memperbincangkan masalah pribadi yang dirasakan oleh masing-mamsing anggota kelompok (Prayitno, Amti, 2009).

Layanan konseling kelompok merupakan layanan konseling perorangan yang pelaksanaannya melalui dinamika kelompok. Dimana ada konselor juga ada klien, jumlah kelompok minimal dua orang dan terjadi hubungan yang hangat, permisif dan penuh keterbukaan hampir sama dengan konseling perorangan. (Prayitno, 2015).

Adapun tujuan dari konseling kelompok adalah berkembangnya kemampuan sosialisasi mahasiswa, khususnya kemampuan berkomunikasinya. (Tohirin, 2013).

Menurut Prayitno (2015), tujuan konseling kelompok terbagi dua: Pertama, tujuan umum. Tujuan konseling kelompok adalah konseling dapat berkembang dalam bidang sosial, khususnya kemampuan berkomunikasi; Kedua, tujuan khusus. Konseling kelompok pada pembahasan masalah pribadi individu peserta kegiatan layanan.

Berdasarkan Tohirin (2013), ada beberapa tahapan dalam melaksanakan konseling kelompok, yaitu: Pertama, perencanaan yang mencakup kegiatan: 
(a)Membuat kelompok. Ketetapan membuat layanan konseling kelompok sama dengan bimbingan kelompok. Anggota dalam konseling kelompok berjumlah antara 8-10 orang dan tidak boleh melebihi. (b) Dapat menyakini klien bahwa konseling kelompok begitu penting agar masalah klien bisa terentaskan,(c) Memposisikan klien dalam kelompok,(d) Memprogramkan jadwal kegiatan,(e) Membuat prosedur layanan, (f) Memfasilitasi layanan, (g) Mempersiapkan kelengkapan administrasi; Kedua, pelaksanaan yang mencakup kegiatan: (a) mengomunikasikan rencana layanan konseling, (b) mengorganisasikan kegiatan layanan konseling kelompok, (c) pelaksanaan konseling kelompok dilaksanankan dengan beberapa tahap : (1)pembentukan, (2) peralihan, (3) kegiatan, dan (4) pengakhiran; Ketiga, kegiatan evaluasi anatar lain : a)menetapkan materi evaluasi, b)menetapkan prosedur evaluasi, c) menyusun instrument evaluasi, d) mengoptimalkan instrument evaluasi, e) mengolah hasil aplikasi instrument; Keempat, melakukan analisis hasil evaluasi yang mencakup kegiatan: a) Membuat norma dan strandar analisis, b) Memproses analisis evaluasi, dan c) membuat hasil analisis; Kelima, keberlanjutan yang mencakup kegiatan : a) menentukan jenis dan kegiatan berikutnya, b) melakukan komunikasi pada pihak-pihak yang terkait tentang tindak lanjut berikutnya, c) melakukan tindak lanjut proses kegiatan berikutnya; Keenam, laporan yang mencakup kegiatan: a) meeengadministrasikan laporan konseling kelompok, b) menginformasikan laporan kegiatan layanan kepada pihak-pihak yang terkait. c) mengkomunikasikan laporan layanan.

Tokoh dari teori realitas adalah William Glasser. William lahir pada tahun 1925. Teori ini menekankan bahwa semua perilaku yang ada pada diri seseorang memiliki tujuan untuk memenuhi satu atau kebutuhan dasar dari dirinya. Terapi realitas merupakan terapi jangka pendek berfokus pada saat sekarang, menekankan kekuatan pribadi, dan jalan bagi anggota kelompok bisa belajar tingkah laku dan lebih realistic (Edi Kurnanto, 2013).

Tanggung jawab merupakan inti dari teori realitas. Tindakan untuk memperbaiki teori realitas, Glasser mengeksplorasi konsep tingkah laku adalah bagaimana mengendalikan persepsi dalam kelompok terhadap dunia luar, mencocokkan antara psikologi dan sikap individu. Glasser percaya bahwa seseorang yang mempelajari itu akan mampu mengendalikan hidupnya (Edi Kurnanto, 2013).

\section{METODE PENELITIAN}

Desain yang digunakan dalam penelitian ini adalah desain pre-test dan post-test group yang polanya seperti berikut:

\section{$\mathrm{O}_{1} \mathrm{X} \mathrm{O}_{2}$}

Keterangan:

$\mathrm{O}_{1}$ : Pre-test diberikan sebelum melakukan Layanan konseling kelompok.

X : Perlakuan/treatment (Layanan konseling kelompok dengan teknik relita).

$\mathrm{O}_{2}$ : Post-test diberikan setelah melakukan Layanan konseling kelompok. 
Penelitian ini dilakukan sebanyak dua kali yaitu sebelum diberikan treatment dan sesudah diberikan treatment. Penelitian yang dilakukan sebelum eksperimen $\left(\mathrm{O}_{1}\right)$ disebut pre-test, setelah ekperimen $\left.\mathrm{CO}_{2}\right)$ disebut post-test.

Populasi dalam penelitian ini adalah seluruh Mahasiswa BK UMN Al Washliyah Medan. Sedang subjek dalam penelitian ini adalah 10 orang mahasiswa yang ditentukan secara purposive sampling.

Pengumpulan data dilakukan melalui angket yang diberikan kepada mahasiswa. Skala atau kuesioner adalah sejumlah pernyataan tertulis yang digunakan untuk memperoleh informasi dari responden, yang terdiri dari angket gaya hidup hedonisme. Untuk menilai jawaban siswa digunakan skala Likert sebagai berikut: Tabel 3.3

\begin{tabular}{|c|c|c|c|c|}
\hline \multirow[t]{2}{*}{ No. } & \multicolumn{2}{|c|}{ Pertanyaan Positif } & \multicolumn{2}{|c|}{ Pertanyaan Negatif } \\
\hline & Skor & Keterangan & Skor & Keterangan \\
\hline 1. & 4 & Sangat Sering & 1 & Sangat Sering \\
\hline 2. & 3 & Sering & 2 & Sering \\
\hline 3. & 2 & Jarang & 3 & Jarang \\
\hline 4. & 2 & Tidak Pernah & 4 & Tidak Pernah \\
\hline
\end{tabular}

\section{HASIL DAN PEMBAHASAN}

Hasil yang dicapai dalam penelitian ini adalah terdapat pengaruh positif layanan konseling kelompok terhadap gaya hidup hedonisme mahasiswa. Dengan menggunakan uji kesamaan dua rata-rata (Uji t).

Uji coba angket berfungsi untuk mengetahui apakah instrument tersebut layak digunakan untuk memperoleh data gaya hidup hedonisme mahasiswa dengan menggunakan Rumus Product moment yang diperhitungkannya adalah sebagai berikut:

Perhitungan Validitas Item Variabel Gaya Hidup Hedonisme Pada Mahasiswa:

$\mathbf{r}_{x y}=\frac{\Sigma X Y-N(\Sigma X)(\Sigma Y)}{\sqrt{\left\{N \Sigma \mathrm{X}^{2}-(\Sigma \mathrm{X})^{2}\right\}}\left\{N \Sigma Y^{2}-(\Sigma Y)^{2}\right\}}$

$\mathrm{r}_{\mathrm{xy}-1}=\frac{55(12757)-(142)(4859)}{\sqrt{\left\{(55)(404)-(142)^{2}\right\}\left\{(55)(436421)-(4859)^{2}\right\}}}$

$\mathrm{r}_{\mathrm{xy}}=\frac{701635-689978}{\sqrt{\{22220-20164\}}\{24003155-23609881\}}$

$r_{\mathrm{xy}}=\frac{11657}{\sqrt{\{2056\}\{393274\}}}$

$r_{x y}=\frac{11657}{\sqrt{80571344}}$

$r_{\mathrm{xy}}=\frac{11657}{28435,39}$

$r_{x y}=0,410$ dinyatakan valid karena $r_{x y}>$ $r_{\text {tabel }}(0,410>0,329)$

Reliabiltas (keterandalan) angket gaya hidup hedonism dihitung dengan menggunakan rumus Alpha :

$r_{11}=\left(\frac{k}{k-1}\right)\left(1-\frac{\sum \alpha b^{2}}{\sigma \tau^{2}}\right)$

$\mathrm{r}^{11}=\left[\frac{26}{26-1}\right]\left[1-\frac{23,980}{130,008}\right]$

$\mathrm{r}^{11}=\left[\frac{26}{25}\right][1-0,184]$

$\mathrm{r}^{11}=1,040 \cdot 0,816$

$r^{11}=0,849$

Dari perhitungan diatas didapat $r_{11}$ sebesar 0,849 dengan $\mathrm{N}=26$ dan konsultasi $=5 \%$ didapat harga $r_{\text {tabel }}=0,388$ karena $r_{11}(0,849)>_{\text {tabel }}(0,329)$ maka perhitungan tersebut adalah reliabel.

Dari hasil perhitungan $\mathrm{Mo}=100,4$ dan $\mathrm{Mi}=90$. Berdasarkan hasil perhitungan Mo $>$ Mi atau 100,4 > 90. Berdasarkan hasil tersebut dapat disimpulkan gaya hidup hedonisme pada mahasiswa sebelum diberi layanan konseling kelompok sebagai perlakuan layanan konseling cenderung tinggi. 
Dari hasil perhitungan diperoleh Mo $=64,6$,dan $\mathrm{Mi}=90$.Berdasarkan hasil perhitungan Mo < Mi atau 64,6 < 90, berdasarkan hasil tersebut dapat disimpulkan bahwa gaya hidup hedonisme pada mahasiswa setelah diberikannya layanan konseling kelompok menurun.

Adapun hipotesis kerja yang penulis kemukakan dalam penelitian ini adalah : ada pengaruh layanan konseling kelompok terhadap gaya hidup hedonisme pada mahasiswa BK UMN Al Washliyah tahun ajaran 2018/2019. Adapun analisis data yang digunakan yaitu analisis uji t dengan rumus sebagai berikut:

$$
t=\frac{M d}{\sqrt{\frac{\sum X^{2 d}}{N(N-1)}}}
$$

Sebelum dilakukannya pengujian hipotesis, terlebih dahulu dicari mean beda dan simpangan baku yaitu membuat tabel data pre-tes dan post-test.

$$
\begin{aligned}
& \mathrm{MD}=\frac{\sum(X B-X A)}{N} \\
& \mathrm{MD}=\frac{\mathbf{3 5 8}}{\mathbf{1 0}} \\
& \mathrm{MD}=\mathbf{3 5 , 8}
\end{aligned}
$$

Maka uji perbedaan (t-test)

$$
\begin{aligned}
& t=\frac{M d}{\sqrt{\frac{\sum X^{2} d}{N(N-1)}}} \\
& t=\frac{358}{\sqrt{\frac{6902}{10(10-1)}}} \\
& t=\frac{358}{\sqrt{\frac{6902}{10(9)}}} \\
& t=\frac{358}{\sqrt{\frac{6902}{90}}} \\
& t=\frac{358}{\sqrt{76,6}} \\
& t=\frac{358}{8,75} \\
& t=40,9
\end{aligned}
$$

Dari hasil perhitungan diperoleh $t_{\text {hitung }}=40,9$ sedangkan harga $t_{\text {tabel }}$ dengan d.b $=\mathrm{N}-1=10-1=9$ pada taraf nyata $=0,05$ diperoleh sebesar 2,262. Sehingga $t_{\text {hitung }}>$ $t_{\text {tabel }}$ atau $(40,9>2,262)$. Berdasarkan hal tersebut maka dapat dinyatakan bahwa hipotesis penelitian ini ada perbedaan gaya hidup hedonisme sebelum diberikan model layanan konseling kelompok teknik realita dengan sesudah diberikan model layanan konseling.

\section{SIMPULAN}

Berdasarkan hasil pengumpulan data dilapangan, setelah dianalisis maka selanjutnya dapat diambil kesimpulan bahwa Model Konseling Kelompok Teknik Realitas tentang Gaya Hidup Hedonisme Pada Mahasiswa BK dapat Memberikan Pemahaman bahayanya gaya hidup hedonisme, itu terlihat dari hasil analisa penelitian dilapangan, yaitu: Gaya hidup hedonisme pada mahasiswa sebelum diberikan layanan konseling kelompok dengan teknik realitas pada mahasiswa BK UMN Al Washliyah berada dikategori tinggi, hal ini dapat dilihat berdasarkan nilai ratarata skor gaya hidup hedonisme mahasiswa sebelum diberi layanan sebesar 100,4 maka gaya hidup hedonisme pada mahasiswa $\mathrm{BK}$ UMN Al Washliyah berada pada kategori tinggi; Gaya hidup hedonisme mahasiswa setelah diberikan layanan konseling kelompok dengan teknik realitas pada mahasiswa BK, hal ini dapat dilihat berdasarkan nilai rata-rata skor setelah diberi layanan sebesar 64,6 maka disimpulkan bahwa gaya hidup hedonisme mahasiswa BK UMN Al Washliyah berada dikategori rendah; Dari hasil perhitungan 
diperoleh $t_{\text {hitung }}=40,9$ sedangkan harga $t_{\text {tabel }}$ dengan d.b $=\mathrm{N}-1=10-1=9$ pada taraf nyata $=00,5$ diperoleh sebesar 2,262. Sehingga $t_{\text {hitung }}>t_{\text {tabel }}$ atau $(40,9>2,262)$. Maka hipotesis penelitian ini " Model layanan konseling kelompok dengan teknik realitas berpengaruh terhadap perubahan perilaku gaya hidup hedonisme mahasiswa BK UMN Al Washliyah Tahun Ajaran 2018/2019.

\section{DAFTAR PUSTAKA}

Chaney, David. (2006). Lifestyle, Sebuah Pengantar Komprehensif. Jalasutra, Yogyakarta

Kurnanto, M. Edi. (2013). Konseling Kelompok. Bandung: Alfabeta

Poespoprodjo. (1999). Filsafat Moral. Bandung: Pustaka Grafika

Prayitno, Erman, Amti. (2009). Dasar-Dasar Bimbingan Dan Konseling. Edisi Revisi. Jakarta: PT Rineka Cipta , (2015). Jenis Layanan dan Kegiatan Pendukung Konseling. Padang: Universitas Negeri Padang

Rahardjo, W., Silalahi, Y.B. (2007). Perilaku Hedonisme Pada Pria Metroseksual Serta Pendekatan Dan Strategi Yang Digunakan Untuk Mempengaruhinya. Pesat Volume 2. Jakarta: Universitas Gunadarma.

Sugiyono. (2010). Metode Penelitian Kuantitatif Kualitatif dan $R \mathcal{E} D$. Bandung: Alfabeta.

Sugiyono. (2013). Metode Penelitian Pendidikan. Bandung: Alfabeta.

Suherli. (2007). Menulis Karangan Ilmiah. Yogyakarta: Arya Duta.

Susanto, B.A. (2001). Potret-Potret Gaya Hidup Metropolis. Jakarta: Kompas.

Tohirin. (2013). Bimbingan dan Konseling di Sekolah dan Madrasah (berbasis integrasi). Jakarta: Raja Grafindo Persada. 